\title{
Influence of Academic Goal Commitment on Late Registrant Success
}

\author{
Ben Littlepage
}

Late registration is widely accepted as an attrition-prone practice with short-sighted institutional gains, yet some late registrants are academically successful and overcome obstacles early in the term. This study investigated whether the academic success of 538 late registrants was influenced by their academic goal, academic level, enrollment status, and gender during the fall 2012 term. Academic success was cumulatively defined as a grade point average of 2.0 or better, completion of all attempted hours and persistence to the following term. Late registrants who enrolled full time and had an academic goal of transferring or pursuing a nursing career pathway were more likely to be successful. Associations with motivation, academic commitment, and goal setting were drawn upon as possible explanations for the success of late registrants.

\section{Introduction and Background}

Each semester, commuter and community college students make the conscious decision, and are often allowed, to register late for classes. Students who register late for classes are less likely to persist and more likely to withdraw before the term ends and hold a lower grade point average (GPA) than those who register earlier (Bolt, 2013; Ford, Stahl, Walker, \& Ford, 2008; Hiller, 2005; Hornik, Saunders, Li, Moskal, \& Dzuiban, 2008; Huang \& Ning, 2012; Safer, 2009; Smith, Street, \& Olivarez, 2002). Angelo's (1990) study represented the only instance where no difference in persistence and academic performance between late registrants and those who registered in a timely fashion was found. Through the review of previously cited literature, late registration was collectively defined as a registration period occurring two weeks prior to the first day of class and ending on the last day to add or drop classes.

As indicated by the aforementioned studies, the relationship between late registration and poor academic performance is clear. The timing of semester course registration correlates with student academic performance and retention (Smith et al., 2002); students who register for classes early in the registration period earn higher grades than students with registration latency (Ford et al., 2008; Safer, 2009).

Late registrants, especially freshmen, withdraw from college before completing

Ben Littlepage (blittlepage@murraystate.edu) is an Assistant Professor \& Coordinator, Postsecondary Education Administration at Murray State University 
a credential at a greater rate (Hornik et al., 2008; Safer 2009). A lower fall term GPA, fewer credit hours enrolled, lower class completion rate, and higher fall-tofall attrition rates are also associated with late registrants (Huang \& Ning, 2012). Late registrants are less likely to 1) enroll in preferred course sections, 2) select desired instructors, and 3) construct schedules conducive to their external and academic obligations (O'Banion, 2012). These students commonly miss opportunities to participate in intensive rapport-building academic advising sessions, freshmen orientation, learning skills refresher courses, and other interventions aimed at promoting retention. The first day and first week of classroom instruction are significant because students most at risk of attrition become engaged and make connections that encourage persistence and success. The need to connect with other students, instructors, and course content comes quickly at the beginning of the semester.

Late registration periods remain at commuter and community college institutions despite the attrition-laden findings previously cited. Smith et al. (2002) mentioned two reasons why late registration exists at the community college level. The first is the ease of access, as demonstrated through rolling admissions and open enrollment. Access is a large component of every community college's mission. The second pertains to state funding for institutions based partially on enrollment. Policies that promote increased enrollment, such as late registration, are viewed as a financial benefit to the institution.

The author of the current study acknowledges late registration is an attritionprone practice with short-sighted institutional gains. Although the registration practice discourages student success, there are late registrants that maintain a GPA at or above the threshold for academic probation, complete the credit hours attempted for the term, and persist to the next semester. Sova (1986) stated late registration alone cannot cause a student to drop out or fail; rather, registering late and failing to persist are caused by others factors. The fact that other confounding variables may play a role in the success of late registrants cannot be overlooked. The literature reviewed does not offer insight into the characteristics of academically successful late registrants. The reviewed literature also compared varying periods of class registration to the academic success of students. The literature reviewed on late registration did not account for the influence motivation and academic goal commitment had on student academic success. This study investigated whether a relationship exists between the academic success of exclusively late registrants, as defined by GPA; completion of attempted hours and one-year persistence; and their academic goals, as defined by declared academic program of study, academic level, enrollment status, and gender.

Educational persistence models like Tinto's (1993) model of voluntary student departure and Bean and Metzner's (1985) nontraditional student attrition model include motivation and goal commitment as influential predictors of student persistence. Tinto wrote that the motivation to graduate from college exerts a positive influence on student persistence. The stronger a person believes he or she can do anything through his or her own efforts, the less likely the student will depart from college. Although much of Tinto's model was discredited in its 
relevancy to commuter and community college students by Braxton, Hirschy, and McClendon (2004), the relationship between goal commitment and persistence was accepted.

Bean and Metzner's (1985) Nontraditional Student Attrition Model is accepted as an educational persistence model for commuter and community college students (Karp, 2011). Bean and Metzner associate goal commitment with the educational aspirations of students in their model. Educational aspirations were defined as the highest level of college education a student plans to obtain. Bean and Metzner cautioned readers that educational aspirations as an isolated predictor could be misleading, and the enrollment status of a student must also be considered when analyzing a student's goal commitment. A report released by the Department of Education (2012) found community college students committed to full-time enrollment and the transfer and completion of a bachelor degree are more likely to be retained until credential completion. Those who attend part time and do not plan to transfer are less likely to persist until credential completion, which further supports earlier findings in the Nontraditional Student Attrition Model.

As stated earlier, Braxton et al. (2004) found much of Tinto's Model of Voluntary Student Departure not applicable to students enrolled at commuter and community colleges. The research group found Tinto's assertions regarding motivation were applicable to non-traditional students. Motivation is manifested by a person's purpose for attending college and the importance placed on oneself for completing college. Motivation is also manifested by the degree of subsequent commitment to the institution, meaning a student's desire to transfer after completing a two-year degree or be accepted into a competitive program will likely motivate him or her to persist until the credential is completed.

Martin, Galentino, and Townsend (2014) sought deeper understanding of the findings of Braxton et al. (2004) with a qualitative study, interviewing 17 graduates of a large community college in the southeastern United States. Martin et al. (2014) found graduates had clear academic goals and a high level of motivation to succeed, managing external demands that could have kept them from graduating. Study participants also felt empowered to solve their own problems and remove obstacles that stood between them and graduating. Participants had a well-defined college and post college plan, either to transfer to a four-year institution or for entry into a specific career path.

Robbins, Lauver, Le, Davis, and Langley (2004) completed a comprehensive meta-analysis inquiry inclusive of psychosocial studies related to student outcomes, as defined by retention and GPA. Academic goals was one of the psychosocial predictor variables reviewed in the meta-analysis. Academic goals was defined as a student's persistence with and commitment to attaining the college degree. Robbins et al. reviewed 33 studies with a total of 20,010 subjects that tested the relationship between academic goals and retention. A moderate, direct correlation of .210 was found. The relationship between academic goals and GPA was reviewed as well in the meta-analysis, using 34 studies with a total of 17,575 subjects. A small, direct correlation of .155 was found. It should be noted subjects in the meta- 
analysis represented multiple academic levels and two and four-year institutions.

The findings from previous studies on late registration failed to focus

exclusively on late registrants who demonstrated academic success. Motivation and academic goal commitment are influential to the academic success of commuter and community college students (Bean \& Metzner, 1985; Braxton et al., 2004). The influence of academic goal commitment on late registrants guided the author's pursuit for new knowledge.

\section{Methods}

Through the literature review, the author suggests late registrants are prone to attrition, low grade point averages, and premature class withdrawals. The purpose of the present research was to identify possible predictors of success for late registrants. The author investigated whether a relationship exists between the academic success of exclusively late registrants, as defined by GPA of 2.0 or higher, completion of attempted hours and one-year persistence, and their academic goals, as defined by declared academic program of study, academic level, enrollment status, and gender.

A binary logistic regression model was used to investigate whether a relationship exists between the dependent and independent variables. Binary logistic regression was used because the dependent variable was dichotomous and categorical. Participants were coded according to four categorical independent variables: academic goal (e.g., transfer, workforce skills development, nursing, or undecided), academic level (e.g., first-time student or returning student), enrollment status (e.g., part-time or full-time), and gender (e.g., male or female). Students pursuing a nursing career pathway were separated from those acquiring workforce-related skills because of the high percentage represented in the sample and the competitive, pre-admission requirements for the nursing program. The dependent variable was academic success. Academic success was defined as the completion of all attempted credit hours, a semester GPA of 2.0 or better, and persistence to the spring term. A GPA of 2.0 or better was interpreted as successful because it served as the threshold necessary to avoid academic probation at the study site. Persistence was defined as course enrollment through the 14th day of the following spring term, otherwise known as the enrollment census date at the study site.

Students defined as late registrants were tracked from fall 2012 until the 14th day of the spring 2013 term. A report was created in the college's enterprise resource planning system to track the academic progress of 538 students who registered for classes within the defined late registration period. The late registration period began two weeks prior to the term and concluded on the last day to add and drop classes.

The west Tennessee community college where the study took place had a fall 2012 enrollment of 3,590 students. Of these students, 1,202 (33.4\%) were males, 2,388 (66.5\%) were females, 1,601 (44.5\%) attended full-time, 1,989 (55.4\%) attended part-time, 1,168 (32.5\%) were first-time students (freshmen 
and transfer), and 2,422 (67.5\%) were returning students (freshmen, sophomores, and readmits). There were 1,161 (32.3\%) students with the academic goal of transferring and therefore pursued either an Associate of Science or Associate of Arts degree. There were 729 (20.3\%) students with the academic goal of acquiring workforce-related skills (excluding nursing) and, therefore, pursued either an Associate of Applied Science or a certificate program. There were 867 students (24.1\%) who were undecided, and 833 (23.2\%) students pursued an Associate of Applied Science in Nursing.

The sample consisted of 538 students that varied according to academic level, academic goal, enrollment status, and gender. All students attended a small, rural community college in west Tennessee and registered for fall 2012 classes during the late registration period.

\section{Results}

Table 1 presents the frequency data for the variables included in the study. The data indicated that only $29.7 \%$ (160 late registrants) of the sample were deemed

TABLE 1

\section{Frequency of Distribution for Variables}

Variable

Variable
Successful late registrants $\mathrm{n}=160$, spring 2013 frequency $(\%)$

$$
\begin{gathered}
68(42.5) \\
27(17) \\
56(35) \\
7(4.5) \\
160(100)
\end{gathered}
$$

Enrollment Status

Full-time

Part-time

Total

$$
\begin{aligned}
& 294(54.6) \\
& 244(45.4)
\end{aligned}
$$

$102(63.8)$ $58(36.2)$ $160(100)$

Academic Level First-time Returning Total

Gender

Male 
academically successful.

The research question was tested, $p<.01$, and a relationship exists between the academic success of exclusively late registrants, as defined by GPA of 2.0 of higher, completion of attempted hours and one-year persistence, and their academic goals, as defined by declared academic program of study and enrollment status. The dependent variable, academic success, was correctly predicted $70.3 \%$ of the times observed by using the binary logistic regression model. Results of the binary logistic regression analysis are displayed in Table 2. Data show significant relationships exist between academic success of late registrants and the goal of transferring, pursuing a nursing career pathway, and full-time enrollment status. The relationship indicates late registrants that plan to transfer and pursue a nursing career pathway and are enrolled full-time were more likely to demonstrate academic success as defined by a GPA of 2.0 or higher, completion of all attempted hours, and enrollment in the following term. The model equation is as follows: $\log (\mathrm{p} / 1-\mathrm{p})=2.552+-1.221$ (transfer $)+-1.529$ (nursing $)+-.585($ full-time enrollment)

\section{TABLE 2}

\section{Variables in the Equation}

$\begin{array}{llllll}\text { Variable } & \text { B } & \text { Wald } & \text { P } & \text { Exp(B) } & \text { 95\% of C.I. } \\ \text { Academic Goal } & - & 12.268 & .017 & - & - \\ \text { Academic Goal-Transfer } & -1.217 & 7.977 & .005 & .296 & {[.127, .689]} \\ \text { Academic Goal-Nursing } & -1.506 & 11.890 & .001 & .222 & {[.094, .522} \\ \text { Academic Level-First Time Student } & -.344 & 3.038 & .081 & .709 & {[.481,1.044]} \\ \text { Enrollment Status-Full Time } & -.584 & 8.196 & .004 & .558 & {[.374, .832]} \\ \text { Constant } & 2.552 & 36.567 & .000 & 12.829 & -\end{array}$

Note. Variables removed from the equation were gender, academic goal-workforce skills, academic goalundecided, academic level-returning student, and enrollment status-part-time

\section{Discussion}

The findings confirm late registrants are at a disadvantage for being academically successful, regardless of gender and academic level. Only $29 \%$ of the original sample persisted to the next term, earned a 2.0 GPA or higher, and completed all credit hours attempted. The early semester interventions, described by O'Banion (2012), are missed by late registrants and, therefore, offer a supporting explanation for the lack of academic success in the sample.

The data suggest academic goal commitment influences the academic success of late registrants. As reported in the literature review, commuter and community college students with a well-defined college plan, as well as a subsequent commitment after the original academic goal is met, were found to be highly 
motivated and likely to be academically successful (Braxton et al., 2004; Martin et al., 2014). Late registrants who chose to transfer after completing an associate's degree or pursue a nursing career pathway must successfully persist through multiple academic goals to fulfill their educational aspiration. Transfer students desire a bachelor's degree, and as such, these students are encouraged to complete an associate's degree, get accepted to another institution, and complete a minimum of 60 additional credit hours. Students pursuing a nursing career pathway must be accepted into a highly competitive associate's degree program, complete a rigorous and fast-paced academic program, and pass a licensure examination before practicing in the field.

Bean and Metzner (1985) cautioned readers that educational aspirations could not solely predict a student's commitment to academic goals. Enrollment status must be considered when analyzing commitment among commuter and community college students. A student's commitment to academic goals can be challenged by external responsibilities, especially for those enrolled part time. A significant relationship between academic success and full-time enrollment status was found.

\section{Implications for Practice}

In order to counteract the documented academic performance limitations for late registrants, enrollment management professionals should consider 1) the implementation of an application deadline prior to the late registration period, 2) allowing time for students with unclear academic goals to participate in intrusive advising, and 3) career counseling and a new student orientation event for late registrants. Leaders of campus advising centers should ask advisees to complete a short questionnaire in advance of the advising session inquiring about the students' motivation and academic goals for attending college. A clear understanding of academic goals will assist advisors with registration activities, while also providing a referral resource to career counseling staff.

First-year experience (FYE) staff are charged with matriculating new college students into the campus culture and coordinating student success interventions (Renn \& Reason, 2013). Depending on the severity of registration latency, students may have missed the intervention and networking opportunities addressed by O'Banion (2012). At the study site, $15 \%$ of the student body registered late for fall 2012 classes; half of the late registrants were first-time students. Late registrants, who are first-time students, may benefit from FYE staff members assigning an "at risk" flag in the academic alert system. FYE staff should consider a follow-up message to late registrants, personally inviting each to participate in an advising session before the enrollment census date. The advising session between the FYE staff person and the late registrant could include many of the materials, referrals, and discussions offered at a new student orientation event. To best assist late registrants, FYE staff should be provided fundamental training in career exploration, academic advising, and goal setting. 


\section{Future Research}

Other confounding variables may influence the academic success of late registrants. The inclusion of more variables specific to commuter student persistence is needed for future research. Variables such as high school GPA, entrance test scores (e.g., ACT, SAT, Compass), access to financial aid subsidies, availability and utilization of support services, external responsibilities off campus (e.g., family, work, volunteerism), external support (e.g., family, work), and time engaged interacting with instructors and advisors have predicted academic success for commuter and community college students in the past (Braxton et al., 2004; Habley et al., 2012). Research inclusive of these variables would broaden the existing knowledge of late registrants.

The incorporation of interval or scaled measures of motivation and commitment to academic goals would offer greater depth in understanding late registrants. Using academic advisors or FYE staff to assess the scaled measure of motivation and commitment throughout an academic term would be beneficial for understanding when and why changes in motivation and commitment occur among late registrants.

The study needs to be expanded to additional commuter and community college sites. The study site was small and rural, and the results from the study may not apply to larger urban commuter and community college settings.

\section{Conclusion}

Late registration remains an attrition-prone practice with short-sighted fiscal gains. Students that register late experience obstacles to academic success early in the term (O'Banion, 2012). While the majority of late registrants are unsuccessful, academic goal commitment can help these students overcome obstacles experienced due to registration latency. Institutions interested in retaining late registrants should adopt an institutionally coordinated, comprehensive approach to student success (Habley et al., 2012). Enrollment management and first-year experience personnel at commuter and community colleges are imperative to coordinating a comprehensive, collaborative effort to address the salient issue of student academic success.

\section{References}

Angelo, D.T. (1990). The relationship between late registration and student persistence and achievement. College and University: The Journal of the American Association of Collegiate Registrars, 65(4), 316-327.

Bean, J.P., \& Metzner, B.S. (1985). A conceptual model of nontraditional student attrition. Review of Education Research, 55, 485-540. 
Bolt, W. (2013). Gauging the success of late registrants in community colleges. Community College Journal of Research and Practice, 37, 608-612.

Braxton, J.M., Hirschy, A.S., \& McClendon, S.A. (2004). Understanding and reducing college student departure. San Francisco, CA: Jossey-Bass.

Ford, G.G., Stahl, K.J., Walker, M.E., \& Ford, A.M. (2008). Better late than never? The relation of registration date to class performance. College Student Journal, 42(2), 402-407.

Habley, W.R., Bloom, J.L., \& Robbins, S. (2012). Increasing persistence: Research-based strategies for college student success. San Francisco, CA: Jossey-Bass.

Hiller, D. (2005). Late registrants: They are prepared and they do come back if successful. Retrieved from http://www.learningace.com/

Hornik, S., Saunders, C., Li, Y., Moskal, P.D., \& Dzuiban, C.D. (2008). The impact of paradigm development and course level on performance in technologymediated learning environments. Informing Science, 11, 35-58.

Huang, T. \& Ning, B. (2012) A study about the relationship between time of application/ registration and college performance [PowerPoint slides]. Retrieved from http:// www.miair.org/web_documents/relation_between_time_of_applic_regist_and_ retention.pdf.

Karp, M.M. (2011). How non-academic supports work: Four mechanisms for improving student outcomes (Report No. 54). New York, NY: Community College Research Center.

Martin, K., Galentino, R., \& Townsend, L. (2014). Community college student success: The role of motivation and self-empowerment. Community College Review 42(3), 221-241.

Northern Virginia Community College (2001). Student retention at NVCC and strategies for improvement. [Research report]. Retrieved from http://www.nv.cc.va.us/oir/reports/sturetentcov.htm

O'Banion, T. (2012). Late registration: May it rest in peace. Community College Journal, 83(1), 26-31.

Renn, K.A. \& Reason, R.D. (2013). College students in the United States: Characteristics, experiences and outcomes. San Francisco, CA: Jossey-Bass.

Robbins, S., Lauver, K., Le, H., Davis, D., Langley, R., \& Carlstrom, A. (2004). Do psychosocial and study skill factors predict college outcomes? A meta-analysis. Psychological Bulletin, 130(2), 261-288.

Safer, A.M. (2009). The effect of late registration for college classes. College Student Journal, 43(4), 1380-1388.

Sova, A.D. (1986). A study of the success rule of late admits in freshmen English at the two-year college. Binghampton, NY: Institute for Community College College Research. (ERIC Document Reproduction Service No. ED275370)

Smith, A.B., Street, M.A., \& Olivarez, A. (2002). Early, regular, and late registration and Community college student success: A case study. Community College Journal of Research and Practice, 26, 261-273.

Tinto, V. (1993). Leaving college: Rethinking the causes and cures of student attrition (2nd ed.). Chicago, IL: The University of Chicago Press. 
United States Department of Education (2012). Characteristics of associate's degree attainers and time to associate's degree (Report No. NCES 2012-271). Retrieved from National Center for Education Statistics website: http://nces.ed.gov/ pubs2012/2012271.pdf

Voorhees, R.A. (1987). Toward building models of community college persistence: A logit analysis. Research in Higher Education, 26, 115-129. 